\title{
PENGARUH POSISI SERAT KACA (FIBERGLASS) YANG BERBEDA TERHADAP KEKUATAN FLEKSURAL FIBER REINFORCED ACRYLIC RESIN
}

\author{
Aprilia Dian Fatimina*, Benni Benyamin ${ }^{* *}$, Helmi Fathurrahman ${ }^{* * *}$
}

\section{Keywords: Fiber Reinforced Acrylic Resin, Flexural Strenght, Fiber Position Fiberglass}

\section{ABSTRACT}

Background: One of factor that increases the flexural strenght of fiber reinforced acrylic resin is a fiberglass position. Fiberglass is one of type that can be used in dentistry. The aim of this was to determine the influence of position of fiberglass to the flexural strenght of fiber reinforced acrylic resin.

Method: This study was in vitro laboratory experimental. Samples was 16 plate spesimens $(65 \times 10 \times 2.5 \mathrm{~mm})$. The study group was divided into 4 group : 3 groups of fiber reinforced acrylic resin were given fiberglass at the upper, middle, and bottom side and 1 control group of resin acrylic without fiberglass.

All of groups would be in the flexural strenght test with a three-point bending test using a universal testing machine.

Result: Based on One Way ANOVA test showed that there were significant value $0.000(p<0.05)$, it concluded that there were significant influence between all the groups. Based on the LSD Post Hoc test showed that there were significant value between all of groups with fiberglass reinforced and control group without fiberglass reinforced. Comparisson between the group that given fiberglass in a upper and middle side with the group that given in bottom side showed value of significant difference $(p<0.05)$.

Conclusion: The result of study was concluded that there was an influence on the position of fiberglass to flexural strenght of fiber reinforced acrylic resin

\section{PENDAHULUAN}

Gigi tiruan merupakan salah satu penanganan yang di berikan pada pasien dengan keluhan kehilangan gigi. Kondisi kehilangan gigi dapat terjadi karena kondisi karies, penyakit periodontal, trauma, dan faktor medik seseorang yang dapat mengganggu fungsi gigi dalam pengunyahan dan estetik wajah. ${ }^{1}$ Gigi tiruan lepasan maupun gigi tiruan cekat telah digunakan 2,9\% penduduk di Jawa tengah pada tahun $2007 .^{2}$

Pemakaian gigi tiruan berbahan resin akrilik polimerisasi heat cured memiliki kelebihan estetik yang baik, aplikasi yang mudah, stabilitas baik dalam rongga mulut, memiliki karakteristik yang baik, dan ekonomis. $^{3}$ Selain mempunyai kelebihan resin akrilik juga mempunyai kekuragan dalam sifat mekanik yaitu fraktur gigi tiruan. ${ }^{4}$ Pada penelitian lain kasus fraktur gigi tiruan sering terjadi pada bagian garis tengah (midline) dari maksila. ${ }^{5}$

Fraktur gigi tiruan dapat disebabkan tekanan impak dimana secara tidak sengaja gigi tiruan jatuh membentur benda keras dan tekanan fleksural yaitu pemberian beban lentur secara berulang pada suatu material yang dapat menimbulkan fraktur apabila meterial tersebut tidak dapat menahan beban lentur lagi. ${ }^{6}$ Kekuatan fleksural adalah gaya per satuan luas yang diberikan pada satu titik fraktur benda yang mengalami pembebanan

*Program Pendidikan Dokter Gigi Fakultas Kedokteran Gigi Universitas Islam Sultan Agung, **Departemen Dental Material Fakultas Kedokteran Gigi Universitas Islam Sultan Agung, *** Departemen Prosthodonti Fakultas Kedokteran Gigi Universitas Islam Sultan Agung

Korespondensi: apriliadian.f@gmail.com 
lentur. ${ }^{7}$ Kekuatan fleksural dapat mengukur secara kolektif kekuatan tarik dan kompresif. ${ }^{8}$

Penelitian kedokteran gigi banyak mengembangkan sifat mekanik dari resin akrilik dengan penambahan material serat (fiber). ${ }^{9}$ Penambahan serat dapat meningkatkan kekuatan impak, fleksural dan fatigue resintant dari sebuah material. ${ }^{10}$ Penambahan jenis serat dalam resin akrilik dapat berupa carbon, metal, aramid dan serat kaca (fiberglass). ${ }^{11}$ Serat kaca adalah salah satu material penambah kekuatan yang terbuat dari serabut-serabut halus dan mengandung kaca. ${ }^{12}$ Penggunaan serat kaca dianggap mempunyai estetik yang baik daripada serat jenis lain. ${ }^{13}$

Peningkatan sifat mekanik dengan serat dapat dipengaruhi oleh kuantitas serat, adesi dari serat, dan posisi serat. ${ }^{9}$ Berdasarkan pernyataan diatas tujuan penelitian ini adalah mengetahui pengaruh posisi serat kaca yang berbeda terhadap kekuatan fleksural fiber reinforced acrylic resin.

\section{METODE PENELITIAN}

Jenis penelitian dalam penelitian ini adalah eksperimental laboratoris in vitro dengan menggunakan rancangan penelitian post test control group design. Subyek penelitian ini terbagi dalam 4 kelompok, yaitu kelompok perlakuan 1 pemberian serta kaca diatas plat resin akrilik, kelompok 2 pemberian serat kaca di tengah plat resin akrilik, dan kelompok 3 pemberian serat kaca di bawah plat resin akrilik, serta 1 kelompok kontrol negatif plat resin akrilik tanpa pemberian serat kaca.

Pembuatan cetakan resin akrilik dilakukan dengan cara mengisi kuvet bagian bawah dengan adonan gips dental plaster. Adonan gips dibuat dengan perbandingan bubuk dan air mengikuti petunjuk pabrik. Malam merah berukuran (pxlxt) $65 \mathrm{~mm} \times 10 \mathrm{~mm} \times 2,5$ $\mathrm{mm}$ diletakan diatas gips. Gips yang telah mengeras akan di oles dengan vaselin dan dilanjutkan pemasangan kuvet antagonis. Pengisian adonan gips dilakukan hingga memenuhi kuvet antagonis dan biarkan sampai mengeras. Kuvet yang telah siap diletakan pada air mendidih selama 5 menit agar malam merah meleleh sehingga cetakan terbentuk (mould).

Pembuatan sampel kelompok perlakuan diawalidengan merendam seratkaca berukuran $63 \mathrm{~mm} \times 3 \mathrm{~mm}$ dalam metil metakrilat selama 15 menit. Tahap selanjutnya membuatan resin akrlik dengan mencampurkan polimer dan monomer menggunakan perbandingan 3:1 dalam pot porselen secara merata. Apabila resin akrilik telah mencapai tahap dough letakan resin akrilik pada mould yang telah dibentuk. Pada kelompok 1 serat kaca yang telah direndam diletakan di bagian atas resin akrilik, kelompok 2 serat kaca diletakan di bagian tengah sedangkan kelompok 3 serat kaca diletakan di bagian bawah. Pemberian kertas selopan dilakukan sebelum kuvet ditutup. Tahapan berikutnya dilakukan proses pressing sebanyak 3 kali menggunakan alat press. Kelebihan resin akrilik setelah proses pressing dapat dikurangi. Setelah kertas selopan dilepas dilanjutkan proses curing

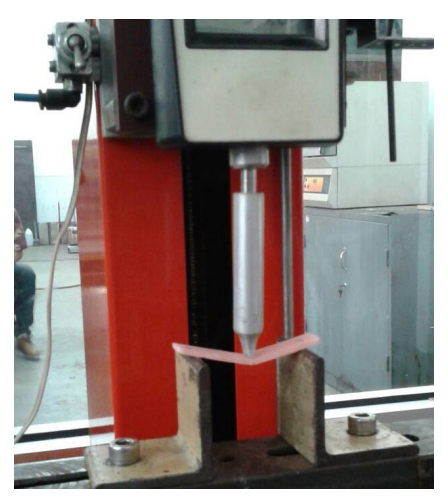

Gambar 1. Uji Kekuatan Fleksural dengan Three point bending test 
dengan merendam kuvet dalam air mendidih selama 20 menit sesuai petunjuk pembuatan resin akrilik. Plat yang telah dibuat dilakukan proses polishing

Pengukuran kekuatan fleksural sampel penelitian menggunakan Universal Testing Machine. Sampel penelitian diberi garis tengah sebagai titik penekanan uji. Kemudian sampel penelitian akan ditumpu pada kedua ujungnya dengan jarak tumpuan $50 \mathrm{~mm}$. Penekanan dilakukan dibagian tengah oleh Universal Testing Machine sampai resin akrilik patah dan alat akan menunjukan nilai beban. Kemudian kekuatan fleksural akan dihitung menggunakan rumus :

$$
S=\frac{3 \mathrm{IP}}{2 \mathrm{bd}^{2}}
$$

Keterangan :

$\mathrm{S}=$ kekuatan fleksural $(\mathrm{N} / \mathrm{mm} 2=\mathrm{Mpa})$;

$\mathrm{I}=$ jarak pendukung $(\mathrm{mm})$;

$\mathrm{P}=\operatorname{beban}(\mathrm{N})$;

$\mathrm{b}=$ lebar batang uji $(\mathrm{mm})$;

$\mathrm{d}=$ tebal batang uji $(\mathrm{mm} 2)$

\section{HASIL PENELITIAN}

Hasil penelitian mengenai pengaruh posisi serat kaca terhadap kekuatan fleksural fiber

Tabel 1. Rata-rata nilai kekuatan fleksural kelompok kontrol dan kelompok perlakuan.

\begin{tabular}{ccc}
\hline Kelompok & Rata-rata (Mpa) & Standar Deviasi \\
\hline Kontrol negative & 490.440 & 11.8003 \\
Serat kaca di bagian atas (I) & 598.980 & 45.0478 \\
Serat kaca di bagian tengah (II) & 601.400 & 32.1503 \\
Serat kaca di bagian bawah (III) & 672.480 & 70.4002 \\
\hline
\end{tabular}

Tabel 2 Uji One Way Anova

\begin{tabular}{lc}
\hline Fleksural & Sig \\
\hline Antar Kelompok & 0,000 \\
\hline
\end{tabular}

Tabel 3 Uji Post Hoc LSD (Least Significant Difference)

\begin{tabular}{llcl}
\hline Kelompok & Kelompok & Sig. & Keterangan \\
\hline Kontrol (-) & Serat kaca bagian atas (I) & .002 & Bermakna \\
& Serat kaca bagian tengah (II) & .001 & Bermakna \\
& Serat kaca bagian bawah (III) & .000 & Bermakna \\
\hline Serat kaca bagian atas (I) & Serat kaca bagian tengah (II) & .934 & Tidak bermakna \\
& Serat kaca bagian bawah (III) & .020 & Bermakna \\
\hline Serat kaca bagian tengah (II) & Serat kaca bagian bawah (III) & .024 & Bermakna \\
\hline
\end{tabular}


reinforced acrylic resin adalah sebagai berikut:

Hasil analisis satstistik menggunakan One Way Anova didapat nilai signifikasi yaitu 0,000 $(p<0,05)$ yang artinya menunjukan terdapat pen posisi serat kaca yang bermakna terhadap kekuatan fleksural fiber reinforced acrylic resin (tabel 2).

Uji beda Pos Hoc LSD dilakukan untuk mengetahui kelompok mana yang berpengaruh secara bermakna ditunjukan Tabel 3.

\section{DISKUSI}

Pada penelitian ini fiber reinforced acrylic resin (kelompok perlakuan) menunjukan nilai kekuatan fleksural yang lebih tinggi daripada resin akrilik tanpa serat kaca (kelompok kontrol negatif). Menurut penelitian lain serat kaca memberikan sifat mekanis yang lebih baik untuk resin akrilik, salah satunya meningkatkan kekuatan fleksural. ${ }^{4}$ Pemakaian serat kaca sebagai material penguat dipengaruhi oleh beberapa hal, yaitu kuantitas serat, adhesi serat, arah struktur serat, dan posisi serat. ${ }^{9}$

Pada penelitian ini dilakukan perendaman serat kaca dalam methyl metacrylate selama 15 menit sebelum ditambahkan pada fiber reinforced acrylic resin. Tujuan perendaman serat kaca dilakukan agar tercipta ikatan yang baik antara serat kaca dengan matriks polimer resin akrilik sehingga terjadi peningkatan kekuatan. ${ }^{4}$ Arah serat kaca juga dapat mempengaruhi sifat mekanik fiber reinforced acrylic resin. Terdapat dua jenis arah serat yaitu undirectional dan bidirectional. Serat kaca dalam penelitian ini dipilih menggunakan serat dengan arah bidirectional karena dapat memperkuat dalam dua arah dan strukturnya dapat bertindak sebagai penghambat retakan di daerah sekitanya. ${ }^{14,15}$

Posisi serat kaca juga merupakan salah satu faktor yang dapat mempengaruhi sifat mekanik dari fiber reinforced acrylic resin. Pada penelitian ini bertujuan untuk mengetahui pengaruh posisi serat kaca terhadap kekuatan fleksural fiber reinforced acrylic resin. Hasil data penelitian menunjukan terdapat pengaruh posisi serat kaca yang bermakna terhadap kekuatan fleksural fiber reinforced acrylic resin.

Kekuatan fleksural tertinggi pada penelitian ini ditunjukan oleh kelompok serat kaca yang diletakan di bagian bawah dengan rata-rata kekuatan fleksural 672,48 Mpa. Kekuatan fleksural didefinisikan sebagai kemampuan sebuah material untuk menahan kombinasi beberapa tekanan, yaitu tekanan tarik (tensile stress), tekanan kompresif (compressive stress), dan tekanan geser (shear stress). ${ }^{16}$

Beban yang diberikan membuat bagian bawah sampel uji mengalami tekanan tarik sehingga sampel uji mengalami elongasi dan permukaan terlihat cembung. Ketika bagian tersebut mencapai tekanan tarik maksimal maka bagian tersebut berpotensi untuk terjadi fracture intiation. ${ }^{17}$ Pemberian serat kaca pada bagian yang mengalami ketegangan dari beban tarik akan meningkatkan kekuatan fleksural lebih baik karena beban yang diberikan akan disalurkan pada serat kaca. ${ }^{18}$ Penelitian lain menyatakan hal serupa bahwa penempatan serat pada bagian dasar yang menerima beban tarik menunjukan kekuatan fleksural yang lebih tinggi karena serat kaca dapat mencegah bagian yang mengalami fracture intiation dengan bertindak sebagai crack arrestor didapat dari struktur serat. ${ }^{15}$

Pada penelitian ini kekuatan fleksural terendah antara kelompok perlakuan terjadi pada kelompok serat kaca di bagian atas dengan rata-rata 598,98 Mpa. Bagian atas sampel adalah bagian yang menerima tekanan kompresi. Tekanan kompresi ini akan 
memberikan beban tekan yang maksimal. ${ }^{16}$ Peletakan serat mendekati permukaan yang menerima beban kompresi menunjukan kekuatan fleksural yang semakin rendah. ${ }^{15}$ Serat kaca yang terletak di daerah atas dan menerima tekanan kompresi tidak terlalu mempengaruhi kekuatan fleksural fiber reinforced acrylic resin disebabkan penekanan yang diberikan tidak disalurkan pada serat kaca. ${ }^{18}$

Hasil kekuatan fleksural pada kelompok serat kaca dibagian tengah menunjukan ratarata 601,40 Mpa, besar tersebut lebih besar dari kelompok serat kaca di bagian atas dan lebih kecil dari kelompok serat kaca di bagian bawah. Bagian tengah spesimen merupakan daerah yang netral dimana daerah tersebut tidak mengalami tekanan tarik maupun tekanan kompresi. ${ }^{17}$ Posisi serat kaca di bagian tengah tidak meningkatkan kekuatan fleksural secara maksimal, hal ini dikarenakan tekanan yang diberikan akan disalurkan pada kedua ujung spesimen. ${ }^{18}$

\section{KESIMPULAN}

Berdasarkan hasil penelitian dapat disimpulkan bahwa terdapat pengaruh posisi serat kaca yang berbeda terhadap kekuatan fleksural fiber reinforced acrylic resin.

\section{DAFTAR PUSTAKA}

1. Khalifa, N., Allen, P.F., Abu-Bakr, N.H. dan AbdelRahman, M.E. Factor associated with tooth loss and prosthodontic status amon sudanese adult. Journal of Oral Science. 2012.54(4):303-312.

2. Dep.Kes.RI.,Laporan Hasil Riset Kesehatan Dasar (RISKESDAS) Nasional. Jakarta:Badan Penelitian dan Pengembangan Kesehatan. 2009.hal:140.

3. Tham,W.L., Chow, W. S.dan Mohd Ishak, Z. A. Simulated body fluid and water absorption effects on poly(methyl methacrylate)/hydroxyapatite denture base composites. eXPRESS Polymer Letters. 2010.4(9): 517-528.
4. Nirwana, I.Kekuatan transversa resin akrilik hybrid setelah penambahan glass fiber dengan metode berbeda. Maj. Ked. Gigi.(Dent. J.).2005. 38(1):1619.

5. Badr, A.A., Ibrahim, A.M. dan Mohamed,G.F. Effect of the curing mode on the clinical performanceand properties of acrylic resin overdenture bases.Cairo Dental Journal.2008.24(2):259-271.

6. El-Sheikh, A.M. dan Al-Zahrani, S.B. Causes of denture fracture : A survey.Saudi Dental Journal.2006.18(3):149-154.

7. Rajj, N. dan D'Souza, M. Comparison of Transverse Strength of Denture Base Resin on Immersion for Varying Time Period in Water and Denture Cleansers - An In Vitro study.Asian Journal of Oral Health \& Allied Science. 2011.1(2):97-100.

8. Gurbuz, O., Unalan, F., Dikbas, I. Comparison of the transverse strength of six acrylic denture resins. OHDMBSC.2010.9 (1): 21-24.

9. Mosharraf, R. dan Givechian, P. Effect of fiber position and orientation on flexural strength of fiber reinforced composite. Journal of Islamic Dental Association of IRAN(JIDA).2011.(24):21-27.

10. Alla, R.K., Sajjan, S., Alluri, V.R., Ginjupalli,K. dan Upadhya, N. Influence of Fiber Reinforcement on the Properties of Denture Base Resins.Journal of Biomaterials and Nanobiotechnology.2013.(4): 9197.

11. Tacir, I.H., Kama, J.D., Zortuk, M. dan Eskimez, S. Flexural properties of glass fibre reinforced acrylic resin polymers. Aust Dent J. 2006.51(1): 52-56.

12. Sitorus, Z. dan Dahar. Improvement of physical and mechanical properties of the hot polimeric acylic resin by adding glass fibre. Dentika Dental Journal. 2012.17(1):24-29.

13. Raszewski, Z. dan Nowakowska, D. Mechanical properties of hot curing acrylic resin after reinforced with different kinds of fibers.International Journal of Biomedical Materials Research.2013.1(1):9-13.

14. Garaoushi, S.K., Lassila, L.V.J. dan Vallittu, P.K. Fibre-reinforced composite in clinical dentistry. The Chinese Journal of Dental Research.2009.12(1):7-14.

15. Mozartha, M., Herda, E., Soufyan, A. Pemilihan resin komposit dan fiber untuk meningkatkan kekuatan fleksural Fiber Reinforced Composite (FRC). Jurnal PDGI. 2010.59(1): 29-34.

16. Mathew, M., Shenoy, K., Ravishankar, K.S. Flexural strenght of E-Glass-reinforced PMMA. International Journal of Experimental Dental Science. 2014.3(1):24-28.

17. Anusavice, K.J. Phillips' Science of Dental Materials. Ed ke-11. Saunders: St. Louis.2003.hal 70-734.

18. Lassila L.V.J. dan Vallittu P.K.The effect of fiber position and polymerization condition on the flexural properties of fiber -reinforced composite. J. Contemp. Dent. Prac.2004.(5)2: 14-26. 